ARTICLE OPEN

\title{
Comparison of adverse events associated with different spacers used with non-extrafine beclometasone dipropionate for
} asthma

Simon Wan Yau Ming ${ }^{1}$, John Haughney ${ }^{2}$, Dermot Ryan $\mathbb{i}^{3,4}$, Shishir Patel ${ }^{5}$, Matthias Ochel ${ }^{5}$, Martina Stagno d'Alcontres ${ }^{1}$, Susannah Thornhill ${ }^{1}$, Janwillem W. H. Kocks (iD) ${ }^{1,6}$ and David Price iD $^{1,2,3}$

Co-prescription of Aerochamber spacer with non-extrafine beclometasone diproprionate (non-EF BDP) is common but unlicensed. We report a comparison of inhaled corticosteroid (ICS)-related adverse events between patients co-prescribed Aerochamber compared to the licensed Volumatic ${ }^{\circledR}$ spacer. We utilised two historical cohorts: questionnaire-based and electronic medical record (EMR)-based, to assess patient-reported and EMR-recorded adverse events in patients with asthma prescribed non-EF BDP. Marginal effect estimate (MEE) was calculated to determine non-inferiority of Aerochamber compared to Volumatic in terms of patientreported oral thrush and hoarseness with margin of 0.13 . Other patient-reported adverse events (sore throat, bruising, weight gain, and coughing), and EMR-recorded adverse events were also assessed. Rate of patient-reported oral adverse events were noninferior in 385 patients prescribed Aerochamber compared to 155 patients prescribed Volumatic (27.7 vs 29.9\%; MEE, $-0.043 ; 95 \%$ $\mathrm{Cl},-0.133$ to 0.047 ). Total patient-reported adverse events did not differ significantly between Aerochamber and Volumatic ( 53.3 vs $49.7 \%$ with $\geq 1$ adverse event). The EMR-based study of 1471 matched pairs of subjects did not show significantly different number of EMR-recorded adverse events between Aerochamber and Volumatic (12.5 vs $12.8 \%$ with $\geq 1$ adverse events). Co-prescribing Aerochamber with non-EF BDP does not increase the risk for patient-reported and EMR-recorded ICS-related adverse events compared to co-prescribing Volumatic.

npj Primary Care Respiratory Medicine (2019)29:3 ; https://doi.org/10.1038/s41533-019-0115-0

\section{INTRODUCTION}

Asthma is a heterogeneous disease characterised by chronic airway inflammation that has a substantial impact on quality of life and healthcare resources. National and international guidelines recommend inhaled corticosteroids (ICS) as the first-line therapy for treatment of asthma. ${ }^{1,2}$ ICS treatment has proven to be efficient at improving lung function, decreasing airway hyperresponsiveness, reducing symptoms, frequency, and severity of exacerbations, and improving patient quality of life. ${ }^{3-5}$ Despite their proven efficacy, ICS can cause both oropharyngeal and systemic adverse events. $^{6-10}$

Oropharyngeal adverse events associated with ICS use include oral candidiasis (oral thrush), hoarseness, dysphonia, pharyngitis, and cough reflex. ${ }^{11-13}$ Oral thrush is a well-documented adverse event associated with regular use of ICS in patients with asthma. ${ }^{6,11,14,15}$ Approximately $5-10 \%$ of patients prescribed ICS reported adverse events in the oral cavity and pharynx, ${ }^{7,11,12}$ with the occurrence of clinically significant oropharyngeal candidiasis as high as $10 \%$ in adults ${ }^{6,16,17}$ and between 1 and $3 \%$ in children. $^{18,19}$ The reduction of the local immune response, ${ }^{20}$ or growth stimulation of Candida albicans ${ }^{21}$ through an increase in salivary glucose, are believed to be responsible for the development of candidiasis. Multiple factors have been reported to contribute to the incidence of oral thrush in patients with asthma, including the type and dose of ICS prescribed, the delivery device used, and patient adherence to medication instructions. ${ }^{22-24}$ This relationship between risk of oral thrush and the type, dose, and delivery device of ICS has also been observed in chronic obstructive pulmonary disorder (COPD) patients. ${ }^{6}$

The use of spacers with pressurised metered dose inhalers (pMDIs) ${ }^{25}$ and careful mouth rinsing after using dry powder inhalers can reduce the risk of oral thrush. ${ }^{18}$ Spacers are recommended by asthma treatment guidelines for patients under the age of 16 years, for those who have problems coordinating actuation, for those prescribed high-dose ICS, for those at risk of suffering from local side effects, and for elderly patients. ${ }^{26}$ The addition of a spacer to a pMDI has proven to consistently reduce aerosol velocity and particle size in the aerosol plume, thus reducing the amount of prescribed therapy deposited in the oropharyngeal cavity and increasing the amount of active compound that reaches the lung. ${ }^{27-29}$ Previous studies have suggested that spacers used with non-extrafine (non-EF) particle ICS may result in reduced rates of oropharyngeal candidiasis. $^{28,30,31}$

Spacers are licensed for use with specific inhalers. Non-EF beclometasone dipropionate (BDP) (Clenil ${ }^{\oplus}$ Modulite) is licensed for use only with the Volumatic ${ }^{\oplus}$ spacer. ${ }^{32}$ However, our previous study found that the Aerochamber spacer has also been frequently prescribed, off-label, in conjunction with Clenil Modulite. ${ }^{33}$ There is concern that the use of unlicensed spacers

\footnotetext{
${ }^{1}$ Observational and Pragmatic Research Institute, Singapore, Singapore; ${ }^{2}$ University of Aberdeen, Aberdeen, UK; ${ }^{3}$ Optimum Patient Care, Cambridge, UK; ${ }^{4}$ University of Edinburgh, Edinburgh, UK; ${ }^{5}$ Chiesi Ltd, Manchester, UK and ${ }^{6}$ General Practitioners Research Institute, Groningen, The Netherlands Correspondence: David Price (dprice@opri.sg)
}

Received: 29 March 2018 Accepted: 5 December 2018

Published online: 08 February 2019 


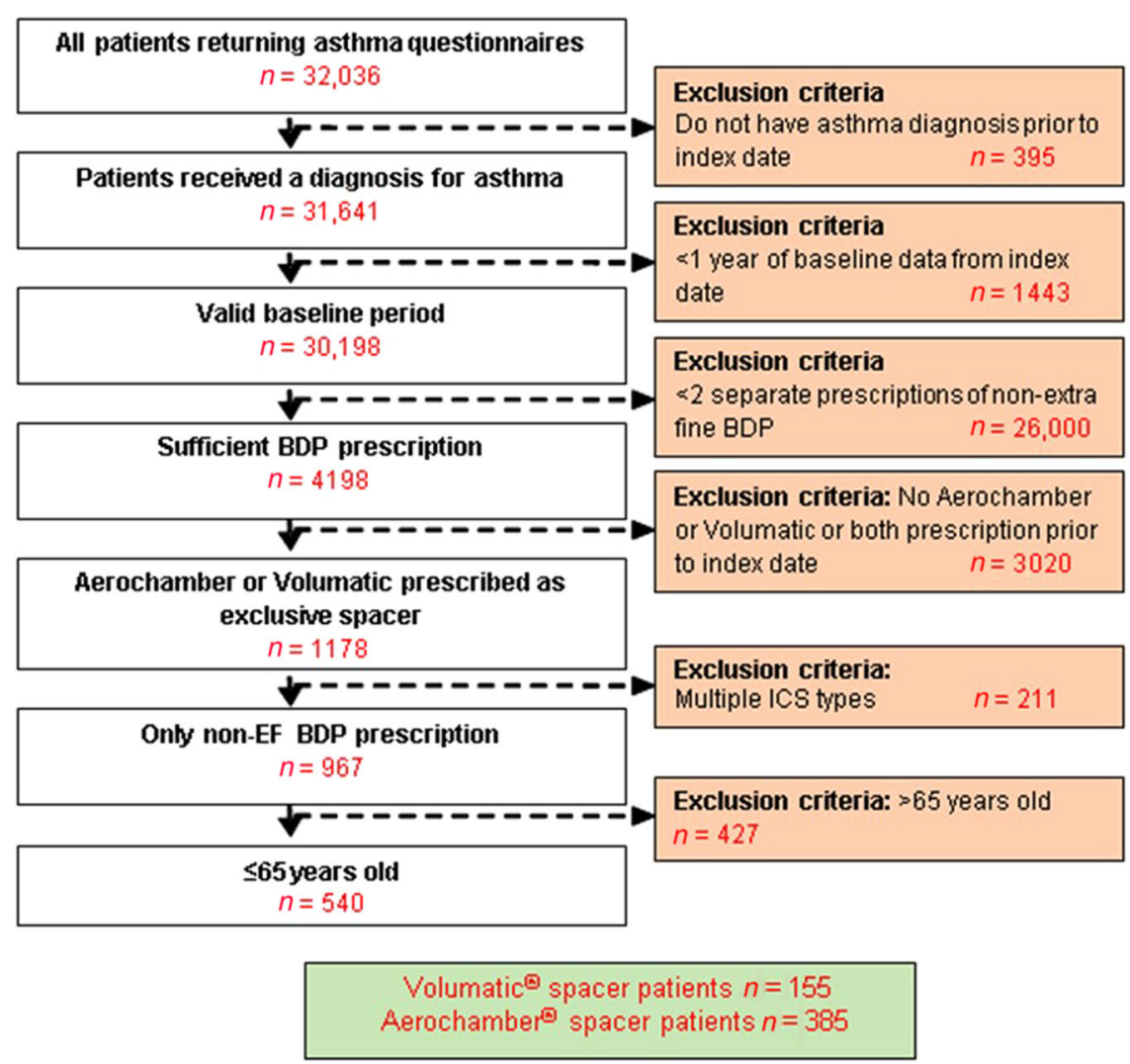

Fig. 1 Patient flow diagram for the questionnaire-based study (primary objective)

may result in a greater number of adverse events compared to the use of licensed spacers. Large spacers, such as the Volumatic device, have been shown to have more effective drug distribution compared to smaller spacers, such as the Aerochamber. ${ }^{34,35}$ However, the ease of use and carriage of the smaller Aerochamber device make it a more attractive choice for both patients and prescribers, even if it is not licensed. ${ }^{36}$ The aim of this study was to characterise both patient-perceived and electronic medical record (EMR)-recorded possible ICS-related adverse events in patients with asthma co-prescribed the licensed Volumatic or the unlicensed Aerochamber spacer with their non-EF BDP therapy. This was conducted using two historical cohort studies: a questionnaire-based study and an EMR-based study for assessment of patient-reported and EMR-recorded adverse events, respectively.

\section{RESULTS}

Study population

The questionnaire-based study consisted of 540 patients who had questionnaire data, collected for routine practice purpose, of whom 385 were prescribed the Aerochamber spacer and 155 were prescribed the Volumatic (Fig. 1). The group prescribed Aerochamber had significantly more female patients (65.7 vs $54.8 \%$ ) and more current smokers (27.2 vs $14.1 \%$ ) but were prescribed lower short-acting $\beta 2$ agonist (SABA) average daily dosage at baseline $(p=0.003)$ (Table 1) compared to the Volumatic group.

A total of 1471 matched pairs were included in the EMR-based study after 1:1 matching (Fig. 2) with the mean age (SD) of 30 (28.2) years and $54 \%$ patients were female (Table 2). More patients in the Aerochamber group were current smokers (17.9 vs $16.0 \%$ ). Patients prescribed the Aerochamber spacer had a higher percentage predicted peak flow than those prescribed the
Volumatic spacer (59.0 vs 52.5 with $\geq 80 \%$ predicted peak flow respectively, $p=0.006$ ). However, the number of patients who experienced at least one severe asthma exacerbation during the 1year baseline period was not significantly different between the Aerochamber- and the Volumatic-prescribed groups (24.5 vs 25.6 respectively, $p=0.650$ ).

Patient-reported oral adverse events

Patient-reported oral adverse events (oral thrush or hoarse voice) were reported in $27.7 \%$ patients co-prescribed the unlicensed Aerochamber compared to $29.9 \%$ of patients co-prescribed the licensed Volumatic spacer. The marginal effect estimate (MEE) was -0.043 (95\% confidence interval $(\mathrm{Cl}),-0.133$ to 0.047$)$. As the upper limit of the $95 \% \mathrm{Cl}$ was less than the pre-defined noninferiority margin of 0.13 , the Aerochamber was determined to be non-inferior to the Volumatic spacer in terms of local oral adverse events (Fig. 3). Non-inferiority was also observed for the outcomes of oral thrush only (MEE, $-0.034 ; 95 \% \mathrm{Cl},-0.079$ to 0.011$)$ and hoarseness only (MEE, $-0.004 ; 95 \% \mathrm{Cl},-0.091$ to 0.083 ).

Total patient-reported adverse events

There were no significant differences in the total number of overall patient-reported adverse events (sore mouth/throat, bruising, abnormal weight gain, and cough in addition to oral thrush and hoarseness) between patients co-prescribed Aerochamber and patients co-prescribed Volumatic spacer (53.3 vs $49.7 \%$ with $\geq 1$ reported event respectively, $p=0.797$ ) from the questionnaire-based study.

\section{EMR-recorded adverse events}

Of the 1471 patients in both groups prescribed Aerochamber and Volumatic, $1287(87.5)$ and $1283(87.2 \%)$ patients did not have any EMR-recorded adverse events, respectively. The number of 
Table 1. Baseline patient characteristics of questionnaire-based study Baseline variable $\quad$ Volumatic ${ }^{\circ}\left(n=\right.$ Aerochamber $^{\circ}(N=\quad P$ value RCC

\begin{tabular}{|c|c|c|c|c|}
\hline ide & $\begin{array}{l}155) \\
\text { volumatic }(n=\end{array}$ & 385) & ue & 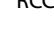 \\
\hline Male gender, $n(\%)$ & $70(45.2)$ & $132(34.3)$ & 0.0181 & 2.1 \\
\hline
\end{tabular}

Age (completed years)

Mean (SD)

42.4 (19.2)

46.7 (15.7)

$48.0(32.0)$

$51.0(20.0)$

Smoking status

Non-smoker, $n(\%)$

$108(72.5)$

$233(62.6)$

20 (13.4)

$38(10.2)$

Ex-smoker, $n$ (\%)

$21(14.1)$

101 (27.2)

Total non-missing (\%) ${ }^{\mathrm{a}} \quad 149(96.1)$

372 (96.6)

BMI $\left(\mathrm{kg} / \mathrm{m}^{2}\right)$

$<18.5, n(\%)$

15 (9.9)

$26(7.0)$

$<18.5-24.99, n(\%)$

53 (35.1)

43 (28.5)

$118(32.0)$

25-29.99, $n$ (\%)

$40(26.5)$

108 (29.3)

$\geq 30, n(\%)$

Total non-missing (\%) ${ }^{\mathrm{a}} \quad 151(97.4)$

117 (31.7)

SABA average daily dosage ( $\mu$ )

$26(16.8)$

44 (28.4)

369 (95.8)

100-200, $n(\%)$

48 (31.0)

110 (28.6)

109 (28.3)

201-400, $n(\%)$

37 (23.9)

$116(30.1)$

50 (13.0)

ICS average daily prescription ( $\mu \mathrm{g}$ BDP equivalent)

$<100, n(\%) \quad 11(7.1) \quad 11(2.9)$

$100-250, n(\%)$

71 (45.8)

174 (45.2)

251-500, $n(\%)$

48 (31.0)

$131(34.0)$

$>500, n(\%)$

$25(16.1)$

69 (17.9)

LABA $\geq 1$ prescription, $n \quad 14(9.0)$

41 (10.6)

7 (4.5)

$11(2.9)$

0.574

0.3

LTRA $\geq 1$ prescription, $n$

(\%)

Eczema diagnosis (1-

year baseline), $n$ (\%)

Rhinitis diagnosis (1-year

baseline), $n$ (\%)

Thrush diagnosis (1-year

baseline), $n$ (\%)

Percentage predicted peak flow

$>=80 \%, n$ (\%)

$50-80 \%, n(\%)$

77 (53.5)

59 (41.0)

8 (5.6)

$139(36.1)$

0.3313

0.4

69 (44.5)

$120(31.2)$

0.0692

1.0

$20(5.2)$

0.6951

0.2

1 (7.1)

0.3901

0.2

177 (49.6)

$168(47.1)$

$12(3.4)$

Total non-missing (\%) ${ }^{\mathrm{a}} \quad 144$ (92.9)

357 (92.7)

Severe asthma exacerbations in 1-year baseline ${ }^{\text {b }}$

$0, n(\%)$

$1, n(\%)$

129 (83.2)

$22(14.2)$

321 (83.4)

45 (11.7)

2 (1.3)

15 (3.9)

$\geq 3, n(\%)$

2 (1.3)

4 (1.0)

The $p$ values were computed from chi-squared test for categorical variables, or Mann-Whitney test for continuous variables and variables presented as both continuous and categorical. Patients were not matched to preserve statistical power. Summary statistics are presented as counts and percentages unless stated otherwise. RCC indicating bias potential of variable when added into the model predicting the outcome

$R C C$ relative change coefficient, $I Q R$ interquartile range, $B M I$ body mass index, SABA short-acting $\beta 2$ agonist, ICS inhaled corticosteroid, $B P D$ beclometasone dipropionate, $L A B A$ long-acting $\beta 2$ agonist, LTRA leukotriene receptor antagonist

${ }^{a}$ Missing data present for this variable, percentages for categorical variables are given as a percentage of the non-missing observations (out of 155 for Volumatic and 385 for Aerochamber)

${ }^{b}$ Defined as occurrence of either: (1) asthma-related unscheduled hospitalisation/accident \& emergency (A\&E) attendance, (2) an acute course of oral steroids, or (3) antibiotics prescribed with lower respiratory consultation patients with exactly one recorded adverse event were 169 (11.5) and $171(11.6 \%)$, respectively, and $15(1.0)$ and $17(1.2 \%)$ had 2 or more adverse events in the Aerochamber and Volumatic groups, respectively (chi-square $p$-value $=0.931$, Table 3 ).

Analysed as a continuous variable (counts of adverse events), the rates of EMR-recorded adverse events were also not significantly different in patients prescribed Aerochamber compared to patients prescribed Volumatic spacer (adjusted rate ratio, $1.28 ; 95 \% \mathrm{Cl}, 0.99$ to 1.65$)$.

\section{DISCUSSION}

This real-life study in a population of patients with asthma provides a unique perspective of both patient-reported and EMRrecorded ICS-related adverse events. Data from both patient questionnaires and EMR demonstrated that the co-prescription of the unlicensed Aerochamber spacer with non-extrafine beclometasone was not associated with higher patient-reported or EMRrecorded adverse events than the co-prescription of the licensed Volumatic device with non-extrafine beclometasone.

The combination of the right medication and the optimal delivery device with the patient's cognitive and physical abilities are essential to ensure optimum therapy delivery. The prescription of devices that are not easily used by patients can result in incorrect inhaler technique, leading to decreased drug delivery, poor disease control, and culminating in decreased therapy adherence. ${ }^{37,38}$ National and international guidelines offer advice on which patients should receive specific therapies. ${ }^{1,26}$ However, these are often not strictly followed by healthcare professionals as patients may be unwilling to carry, or unable to use the device. Off-label and unlicensed prescriptions may also be given due to the lack of a licensed therapy available for a patient's age group. ${ }^{36}$ Our recent study found that national guidelines for spacer prescription were not followed for a large proportion of patients prescribed non-EF BDP. ${ }^{33}$ Of those patients who were prescribed spacers, the majority were prescribed the unlicensed Aerochamber spacer $(59.0 \%)$ followed by the licensed Volumatic device $(18.9 \%){ }^{33}$

A major concern with unlicensed prescriptions is the potential for side effects. Several studies have reported an increased incidence of oral thrush in patients with asthma associated with ICS dose. 22-24,31 To account for this, we adjusted our analysis for ICS dose in the questionnaire-based study and matched for ICS daily dose in the EMR-based study. Thus, any difference in ICSrelated adverse events would not have been caused by the ICS dose. Other reported local side effects of ICS use include dysphonia, cough reflex, and pharyngitis. These are also considered to be an immediate cause of clinical discomfort, which in turn reduce patient adherence to therapy, possibly resulting in a decrease in asthma control. ${ }^{7,11,12}$ This study clearly demonstrated that this was not the case for co-prescription of the unlicensed Aerochamber spacer with non-EF BDP asthma therapy. In terms of patient-perceived occurrence of oral thrush and hoarseness, the Aerochamber was non-inferior to the licensed Volumatic spacer. This was further confirmed by doctor-recorded data (diagnostic read codes), where patients prescribed the Aerochamber spacer did not suffer significantly more ICS-related adverse events than those prescribed the Volumatic spacer.

It is very likely that the range and extent of ICS-related adverse events, as experienced by patients, are underestimated. 9,12,39 The short duration of clinical trials and the stringent inclusion criteria often limit the quality and quantity of data on adverse events. ${ }^{40,41}$ Similarly, patient-perceived ICS-associated adverse events may not be detected during routine clinical practice as patients are often reluctant to discuss their concerns about medication with their physicians. ${ }^{42}$ Discordance and lack of patient-prescriber communication may cause patients to titrate their medication or selfmedicate, reducing disease control. ${ }^{12}$ This existing disparity 


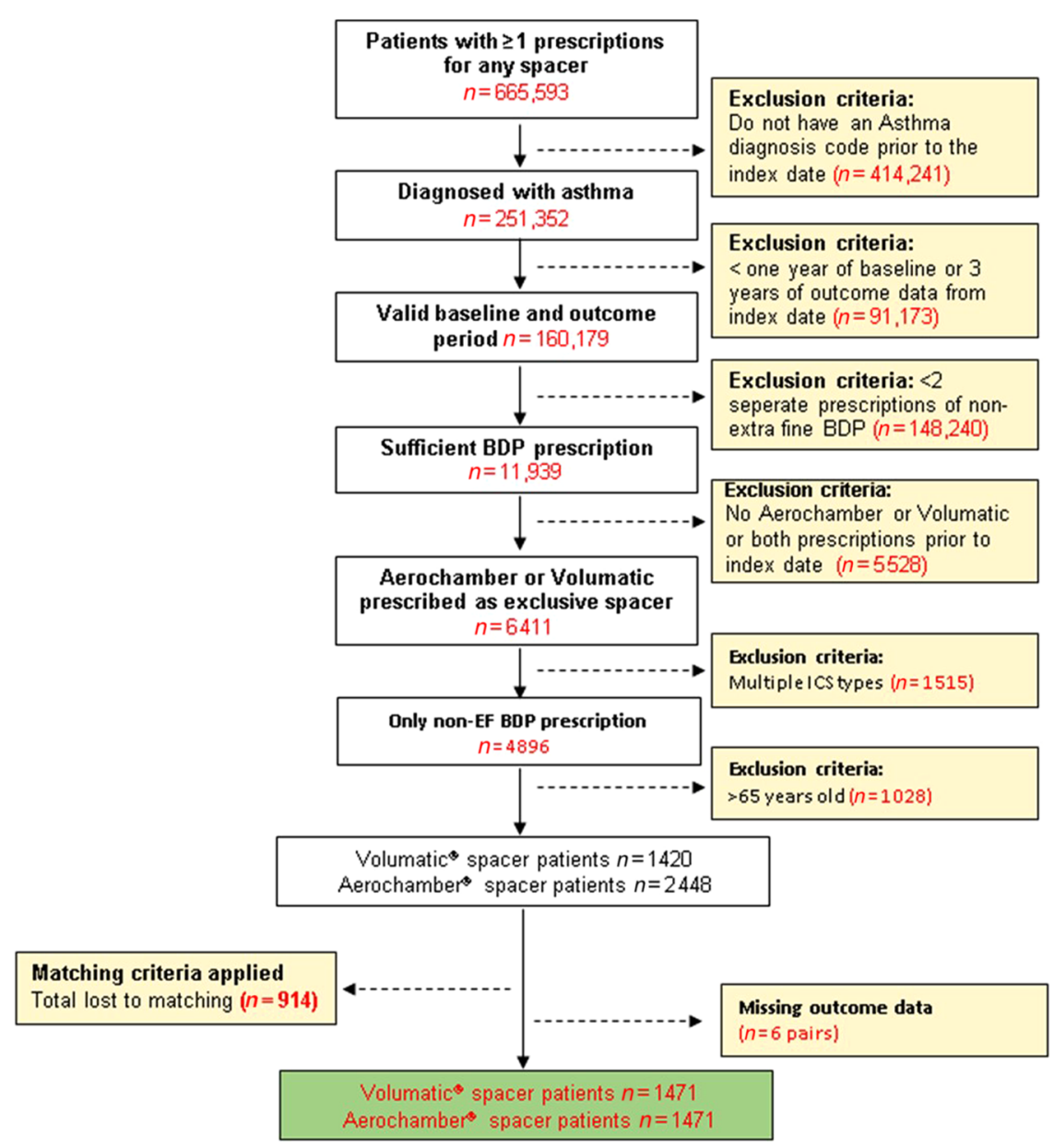

Fig. 2 Patient flow diagram for the electronic medical record (EMR)-based study (secondary objective)

between doctors and patients, with respect to their approach to drug-related adverse events, can be tackled via better patient understanding of their treatment benefits and of potential adverse effects, and with prescribers trying to better understand the concerns of patients. ${ }^{43}$ Previous reports have suggested differences in patient- versus doctor-reported adverse events, ${ }^{44}$ and it is therefore important to integrate self-reported patient questionnaires as a key tool for investigating adverse events. The use of both patient questionnaires and physician-recorded adverse events makes this study unique.

Real-world studies assess the results of therapy under conditions of usual care that are not subjected to the selection of patients through restrictive eligibility criteria as occurs in clinical trials. Although the Optimum Patient Care Research Database (OPCRD) is a well-maintained and validated database, we cannot rule out the possibility of inaccurate or missing data. The outcomes were studied over 3 full years for the cohort study to balance seasonal influences on outcome measures. However, the real-life nature of this study also means that although spacer prescriptions were identified, it is not guaranteed that the prescriptions were filled or that the spacers were used. A limitation inherent to observational studies is the possibility of unrecognised confounding factors or influences in prescribing that were not accounted for such as inhaler technique. Lastly, only read-coded adverse events would have been detected in the EMRbased study. This is however unlikely to be unbalanced between either spacer arms and thus is not expected to significantly affect the finding of this study.

The current study focused on the adverse events of spacer coprescription with non-extrafine beclometasone prescription for asthma. More recent devices are able to generate ICS aerosol as extrafine particles which has been previously reported by various studies to have comparable to superior efficacy and safety compared to non-extrafine formulation. ${ }^{15,45}$ Further studies will be required to extend the finding of this study to spacer use with ICS delivered as extrafine particles.

In conclusion, this study found that co-prescription of the unlicensed Aerochamber spacer with non-extrafine beclometasone dipropionate therapy for asthma did not increase the risk of developing patient-reported or EMR-recorded ICS-related adverse events, as compared to co-prescription of the licensed Volumatic device.

\section{METHODS}

Data source

The study utilised a large UK primary care database, the OPCRD (www. opcrd.co.uk). ${ }^{46}$ The OPCRD currently comprises fully anonymous, longitudinal medical records for over 4.5 million patients from over 600 primary care practices across the United Kingdom. The OPCRD contains two types of data: (1) routinely recorded clinical data and (2) questionnaire data (collected as part of routine patient data collection) from over 55,700 patients with respiratory conditions. This enables real-life studies to draw on information from both perspectives, ensuring a more complete answer to the questions posed. The OPCRD is approved by the Health Research Authority of the UK NHS for clinical research use (Research Ethics Committee (REC) reference: 15/EM/0150). Records contain complete prescribing, coded diagnostic, and clinical information, as well as information on tests requested, laboratory results, and referrals made at or following on from each consultation. ${ }^{47}$ 
Table 2. Matched baseline patient characteristics of EMR-based study

\begin{tabular}{|c|c|c|c|}
\hline Baseline variable & $\begin{array}{l}\text { Volumatic }(n= \\
1471)\end{array}$ & Aerochamber $^{\circ}(N=1471)$ & $P$ value \\
\hline Male gender ${ }^{\mathrm{a}}, n(\%)$ & $678(46.1)$ & $678(46.1)$ & 1.0000 \\
\hline \multicolumn{4}{|l|}{ Age (completed years) ${ }^{\mathrm{a}}$} \\
\hline Mean (SD) & $30.0(28.2)$ & $30.0(28.2)$ & \multirow[t]{2}{*}{0.9079} \\
\hline Median (IQR) & $11.0(52.0)$ & $11.0(53.0)$ & \\
\hline \multicolumn{4}{|l|}{ Smoking status } \\
\hline Non-smoker, $n(\%)$ & $1058(78.8)$ & $980(74.4)$ & \multirow[t]{4}{*}{0.0064} \\
\hline Ex-smoker, $n(\%)$ & $69(5.1)$ & $102(7.7)$ & \\
\hline Current smoker, $n$ (\%) & $215(16.0)$ & $236(17.9)$ & \\
\hline Total non-missing $(\%)^{\mathbf{b}}$ & $1342(91.2)$ & 1318 (89.6) & \\
\hline \multicolumn{4}{|l|}{ BMI $\left(\mathrm{kg} / \mathrm{m}^{2}\right)$} \\
\hline$<18.5, n(\%)$ & $350(37.4)$ & $363(38.1)$ & \multirow[t]{5}{*}{0.5190} \\
\hline $18.5-24.99, n(\%)$ & $121(12.9)$ & $129(13.6)$ & \\
\hline $25-29.99, n(\%)$ & $122(13.0)$ & $103(10.8)$ & \\
\hline$\geq 30, n(\%)$ & $342(36.6)$ & $357(37.5)$ & \\
\hline Total non-missing $(\%)^{\mathbf{b}}$ & $935(63.6)$ & $952(64.7)$ & \\
\hline \multicolumn{4}{|l|}{ SABA average daily dosage $(\mu \mathrm{g})$} \\
\hline$<100, n(\%)$ & $216(14.7)$ & $210(14.3)$ & \multirow[t]{4}{*}{0.5738} \\
\hline $100-200, n(\%)$ & $374(25.4)$ & $393(26.7)$ & \\
\hline $201-400, n(\%)$ & $514(34.9)$ & $530(36.0)$ & \\
\hline$>400, n(\%)$ & 367 (24.9) & $338(23.0)$ & \\
\hline \multicolumn{4}{|c|}{ ICS average daily prescription ( $\mu \mathrm{g}$ BDP equivalent) ${ }^{\mathrm{a}}$} \\
\hline$<100, n(\%)$ & $208(14.1)$ & $208(14.1)$ & \multirow[t]{4}{*}{1.0000} \\
\hline $100-250, \mathrm{n}(\%)$ & $617(41.9)$ & $617(41.9)$ & \\
\hline $251-500, n(\%)$ & $351(23.9)$ & $351(23.9)$ & \\
\hline$>500, n(\%)$ & $295(20.1)$ & $295(20.1)$ & \\
\hline LABA $\geq 1$ prescription, $n(\%)$ & $215(14.6)$ & $223(15.2)$ & 0.6786 \\
\hline LTRA $\geq 1$ prescription, $n$ (\%) & $111(7.5)$ & $122(8.3)$ & 0.4527 \\
\hline $\begin{array}{l}\text { Eczema diagnosis (1-year } \\
\text { baseline), } n(\%)\end{array}$ & $669(45.5)$ & $613(41.7)$ & 0.0373 \\
\hline $\begin{array}{l}\text { Rhinitis diagnosis (1-year } \\
\text { baseline), } n(\%)\end{array}$ & $296(20.1)$ & $320(21.8)$ & 0.2768 \\
\hline $\begin{array}{l}\text { Thrush diagnosis (1-year } \\
\text { baseline), } n(\%)\end{array}$ & $77(5.2)$ & $70(4.8)$ & 0.5536 \\
\hline \multicolumn{4}{|c|}{ Percentage predicted peak flow } \\
\hline$>=80 \%$ & $576(52.5)$ & $641(59.0)$ & \multirow[t]{4}{*}{0.0064} \\
\hline $50-80 \%$ & $447(40.7)$ & $372(34.2)$ & \\
\hline$<=50 \%$ & $72(6.6)$ & $74(6.8)$ & \\
\hline Total non-missing $(\%)^{b}$ & $1099(74.8)$ & $1,087(73.9)$ & \\
\hline \multicolumn{4}{|c|}{ Severe asthma exacerbations in 1-year baseline ${ }^{c}$} \\
\hline $0, n(\%)$ & $1095(74.4)$ & $1111(75.5)$ & \multirow[t]{4}{*}{0.6499} \\
\hline $1, n(\%)$ & $245(16.7)$ & $248(16.9)$ & \\
\hline $2, n(\%)$ & $83(5.6)$ & $72(4.9)$ & \\
\hline$\geq 3, n(\%)$ & $48(3.3)$ & $40(2.7)$ & \\
\hline
\end{tabular}

The $p$ values were computed from chi-squared test for categorica variables, or Mann-Whitney test for continuous variables and variables presented as both continuous and categorical. Summary statistics were presented as counts and percentages unless stated otherwise

$E M R$ electronic medical record, $I Q R$ interquartile range, $B M I$ body mass index, SABA short-acting $\beta 2$ agonist, ICS inhaled corticosteroid, $B P D$ beclometasone dipropionate, $L A B A$ long-acting $\beta 2$ agonist, LTRA leukotriene receptor antagonist

${ }^{\text {a }}$ Matching variables

${ }^{b}$ Missing data present for this variable, percentages for categorical variables are given as a percentage of the non-missing observations (out of 1471 patients in both groups)

'Defined as occurrence of either: (1) asthma-related unscheduled hospitalisation/accident \& emergency (A\&E) attendance, (2) an acute course of oral steroids, or (3) antibiotics prescribed with lower respiratory consultation

\section{Study design}

This was a post-authorisation safety study utilising two separate historical study designs to achieve the objectives. The first was a historical study involving routine questionnaire data stored in the OPRCD to compare patient-reported ICS-related adverse events for asthma patients prescribed non-EF BDP with either a Volumatic or an Aerochamber spacer. This consisted of a 1-year baseline period for patient characterisation, concluding at the index date, defined as the date of return of the asthma questionnaire.

The second design was a historical EMR-based study to compare physician-recorded outcomes, composed of a 1-year baseline period for characterisation and matching, followed by a 3-year outcome period for detection of adverse events. The index date was defined as the date of first spacer prescription (Volumatic or Aerochamber).

The study protocol was overseen by an independent steering committee and registered with the European Network of Centers for Pharmacoepidemiology and Pharmacovigilance (trial registration number EUPAS13194) and the Anonymous Data Ethics Protocols and Transparency (ADEPT) committee (Ref: ADEPT0517) prior to data extraction.

\section{Patients}

For the questionnaire-based study, eligible patients were aged $\leq 65$ years, with a Read code (clinical coding system within UK's primary care) confirmed asthma diagnosis. They received $\geq 2$ separate non-EF BDP (Clenil Modulite) prescriptions with one prescription for a spacer (Volumatic or Aerochamber) during the baseline year prior to the date of the questionnaire and had 2 years of continuous practice data (comprising $\geq 1$ year of data prior to the questionnaire).

Eligible patients of the EMR-based study were aged $\leq 65$ years, with a Read code confirmed asthma diagnosis. They received $\geq 2$ separate non-EF BDP (Clenil Modulite) prescriptions in the baseline year and another $\geq 2$ prescriptions in 1 year after index. They were prescribed either Volumatic or Aerochamber spacer at the index date and had 4 years of continuous practice data (comprising $\geq 1$ year of baseline data and 3 years of outcome data).

Patients were excluded from both studies if they received prescriptions for different ICS or fixed-dose combination) ICS/LABA (long-acting $\beta$ agonist) therapy or were ever prescribed both Volumatic and Aerochamber spacers (Supplementary Table 1, Supplementary Table 2, Figs. 1 and 2).

\section{Outcome measures}

The primary objective was to determine non-inferiority of non-EF BDP coprescribed with an Aerochamber spacer, compared to the Volumatic spacer, in terms of the frequency of patient-reported oral thrush or hoarseness via the asthma questionnaire over a single year. Other adverse events captured via the questionnaire included sore mouth/throat, bruising, abnormal weight gain, and cough.

The secondary objective was to compare EMR outcomes for non-EF BDP co-prescribed with either the Volumatic or the Aerochamber spacer in the EMR-based study. Read codes for adverse events to non-EF BDP, as defined in the product information sheet ${ }^{32}$ (oral thrush, adrenal suppression diagnosis, osteoporosis/osteopenia, anxiety/depression, cataracts, and glaucoma) over a 3-year period were extracted from the OPCRD.

\section{Adjustment and matching}

For the questionnaire-based study, patients in each spacer group were compared following adjustment for variables selected from those with the highest relative change in coefficient. The final variables used for adjustment were gender, ICS average dose, and smoking status, selected based on clinical judgement and baseline balance. Matching was not conducted for the questionnaire-based study to preserve statistical power due to sample size.

For the EMR-based study, exact matching for categorical variables and matching within a maximum calliper for numeric variables were used to match patients using 1:1 nearest neighbour matching, without replacement. Matching variables such as demographic data, disease co-morbidity, and indicators of disease severity were considered for selection using a combination of baseline data analysis and predictive modelling of the baseline data in relation to the outcome variable (independent of treatment group). The final criteria settled on a mix of direct and propensity score matching (Supplementary Table 3).

\section{Statistical analysis}

The study was powered using the occurrence of oral thrush as the representative adverse event. The occurrence of adverse events (34\%) was based on the oropharyngeal adverse events in users of ICS in a real-life setting reported in the literature. ${ }^{9,48}$ With sample sizes of at least 293 and 147, a two-group large-sample normal approximation test of proportions with a one-sided 0.025 significance level would have $80 \%$ power to reject 


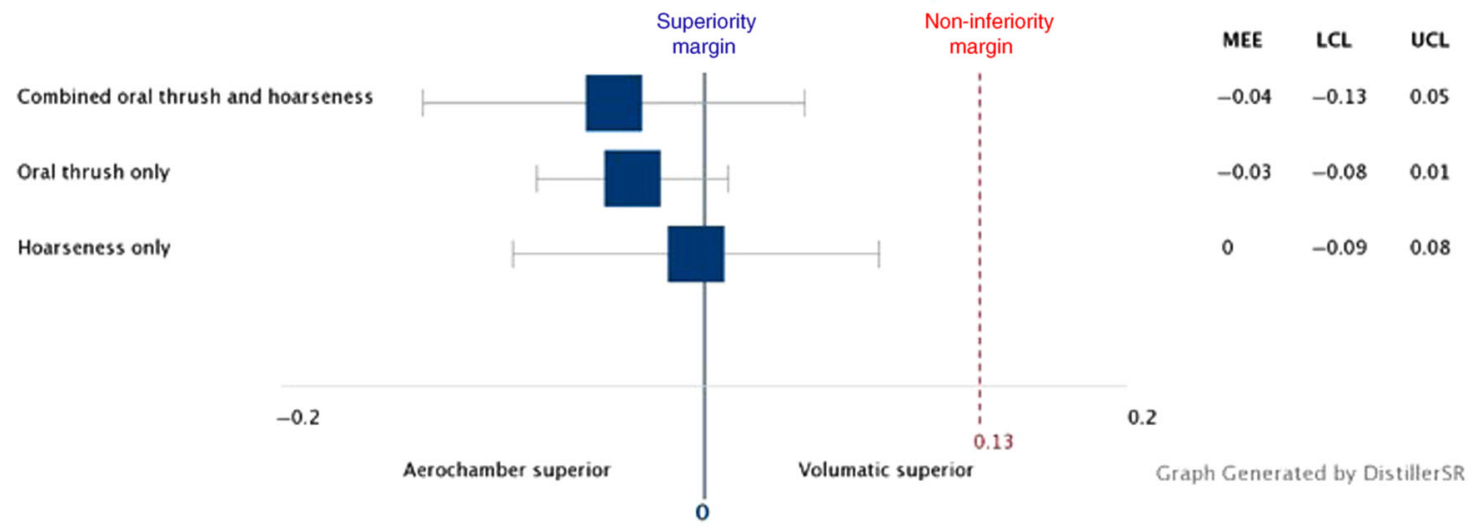

MEE: Marginal Effect Estimate; LCL: Lower Confidence Limit; UCL: Upper Confidence Limit

Fig. 3 Non-inferiority of Aerochamber compared to Volumatic in patient-reported oral adverse events occurrence. Box indicates marginal effect estimate (MEE) value and whiskers indicate confidence intervals

Table 3. Number of EMR-recorded adverse events in matched patients aged 65 years or under

\begin{tabular}{|c|c|c|c|c|}
\hline $\begin{array}{l}\text { Number of adverse events, } \\
n(\%)\end{array}$ & 0 & 1 & $2+$ & $P$ value \\
\hline \multicolumn{5}{|c|}{ Spacer device ( $n=1471$ each arm) } \\
\hline Volumatic & $1283(87.2)$ & $171(11.6)$ & $17(1.2)$ & 0.931 \\
\hline Aerochamber & 1287 (87.5) & 169 (11.5) & $15(1.0)$ & \\
\hline
\end{tabular}

the null hypothesis that the test and the standard are not equivalent (the difference in proportions, $\mathrm{pT}-\mathrm{pS}$, is 0.130 or farther from zero in the same direction).

All analyses were carried out using IBM SPSS Statistics version 21 (IBM SPSS Statistics, Feltham, Middlesex, UK), SAS version 9.3 (SAS Institute, Marlow, Buckinghamshire, UK), and Microsoft Office Excel 2013 (Microsoft Corp., Redmond, Washington, USA). Forest Plot was generated with DistillerSR Forest Plot Generator from Evidence Partners.

MEE of spacer type (Aerochamber or Volumatic) on the reported oral thrush/hoarse voice incidence was calculated to determine non-inferiority in the primary outcome analysis. The MEE was calculated from predictions of the model at fixed values of the covariates and averaging over the remaining covariates to obtain an interval where the result was likely to lie. Chi-square test was utilised to obtain the odds ratio of adverse events identified from the EMR (EMR-recorder adverse events). Poisson regression was utilised to calculate the rate ratio of EMR-recorded adverse events, adjusted for osteoporosis and anxiety/depression diagnosis. The $p$ value of $<0.05$ was considered statistically significant.

\section{Reporting summary}

Further information on experimental design is available in the Nature Research Reporting Summary linked to this article.

\section{DATA AVAILABILITY}

All relevant data are within the paper and the supporting information files. The dataset supporting the conclusions of this article was derived from the UK Optimum Patient Care Research Database (www.opcrd.co.uk). We do not have permission to give public access to these databases; however, researchers may request access for their own purposes. Request for access to OCPRD can be made via the OCPRD website (https://opcrd.co.uk/our-database/data-requests/) or via the enquiries email info@opcrd.co.uk. In accordance with the terms of the agreement signed by OPCRD and OPRI, datasets used in the study must be destroyed within 1 year of availability. The OPCRD has ethical approval from the National Health Service (NHS) Research Authority to hold and process anonymised research data (Research Ethics Committee reference: 15/EM/0150). This study was approved by the Anonymised Data Ethics Protocols and Transparency (ADEPT) committee-the independent scientific advisory committee for the OPCRD, commissioned by the Respiratory Effectiveness Group. The study was designed, implemented, and registered in accordance with the criteria of the European Network of Centres for Pharmacoepidemiology and Pharmacovigilance (ENCePP) (registration number: EUPAS13194).

\section{ACKNOWLEDGEMENTS}

The authors would like to extend their acknowledgement to Dr. Antony Hardjojo for proof-reading this manuscript. This study is funded by Chiesi Limited.

\section{AUTHOR CONTRIBUTIONS}

D.P. is the chief scientist of the study and contributed to the design and initiation of this project. S.W.Y.M. is the project coordinator and responsible for the overall conduct and data analysis for the study. J.H., D., S.P., J.W.H.K., and M.O. provided their scientific expertise throughout the design and progress of the project. M.S.d'.A. and S.T. are responsible for the drafting and writing of the manuscript.

\section{ADDITIONAL INFORMATION}

Supplementary information accompanies the paper on the npj Primary Care Respiratory Medicine website (https://doi.org/10.1038/s41533-019-0115-0).

Competing interests: D.P. has board membership with Aerocrine, Amgen, AstraZeneca, Boehringer Ingelheim, Chiesi, Mylan, Mundipharma, Napp, Novartis, Regeneron Pharmaceuticals, Sanofi Genzyme, Teva Pharmaceuticals; consultancy agreements with Almirall, Amgen, AstraZeneca, Boehringer Ingelheim, Chiesi, GlaxoSmithKline, Mylan, Mundipharma, Napp, Novartis, Pfizer, Teva Pharmaceuticals, Theravance; grants and unrestricted funding for investigator-initiated studies (conducted through Observational and Pragmatic Research Institute Pte Ltd) from Aerocrine, AKL Research and Development Ltd, AstraZeneca, Boehringer Ingelheim, British Lung Foundation, Chiesi, Mylan, Mundipharma, Napp, Novartis, Pfizer, Regeneron Pharmaceuticals, Respiratory Effectiveness Group, Sanofi Genzyme, Teva Pharmaceuticals, Theravance, UK National Health Service, Zentiva (Sanofi Generics); payment for lectures/speaking engagements from Almirall, AstraZeneca, Boehringer Ingelheim, Chiesi, Cipla, GlaxoSmithKline, Kyorin, Mylan, Merck, Mundipharma, Novartis, Pfizer, Regeneron Pharmaceuticals, Sanofi Genzyme, Skyepharma, Teva Pharmaceuticals; payment for manuscript preparation from Mundipharma, Teva Pharmaceuticals; payment for the development of educational materials from Mundipharma, Novartis; payment for travel/accommodation/meeting expenses from Aerocrine, AstraZeneca, Boehringer Ingelheim, Mundipharma, Napp, Novartis, Teva Pharmaceuticals; funding for patient enrolment or completion of research from Chiesi, Novartis, Teva Pharmaceuticals, Zentiva (Sanofi Generics); stock/stock options from AKL Research and Development Ltd which produces phytopharmaceuticals; owns $74 \%$ of the social enterprise Optimum Patient Care Ltd (Australia and UK) and 74\% of Observational and Pragmatic Research Institute Pte Ltd (Singapore); and is peer reviewer for grant committees of the Efficacy and Mechanism Evaluation programme, and Health Technology Assessment. D.R. has received support to attend meetings, delivered educational events on behalf of or provided consultancy to: AZ, 
Chiesi, TEVA, Trudel Medical, Novartis, Bl, Optimum Patient Care, MEDA/Mylan, Stallergenes. J.W.H.K. reports grants and personal fees from AstraZeneca, grants and personal fees from Boehringer Ingelheim, grants from Chiesi, grants and personal fees from GSK, grants and personal fees from Novartis, grants from Mundi Pharma grants from TEVA, outside the submitted work. J.H. reports grants and research supports from Boehringer Ingelheim, GSK, and Teva; and Honoria or consultation fees from AZ, Boehringer Ingelheim, Cipla, Chiesi, Mundipharma, Novartis, Pfizer, Sanofi, and Teva. S.P. and M.O. are employed by Chiesi, the sponsor of the study. S.W.Y.M., M. S.d'.A., and S.T. are past employees of the Observational and Pragmatic Research Institute, which has conducted paid research in respiratory disease on behalf of the following organisations in the past 5 years: Anaxys, AstraZeneca, Boehringer Ingelheim, British Lung Foundation, Chiesi, Circassia (formerly Aerocrine), GlaxoSmithKline, Harvey Walsh, Mapi, Morningside Healthcare, Mundipharma, Mylan (formerly Meda), Napp, Novartis, Orion, Plymouth University, Regeneron, Respiratory Effectiveness Group, Roche, Sanofi, Takeda, Teva, University of East Anglia, Zentiva (a Sanofi company).

Publisher's note: Springer Nature remains neutral with regard to jurisdictional claims in published maps and institutional affiliations.

\section{REFERENCES}

1. Global Initiative for Asthma. 2017 GINA Report, Global Strategy for Asthma Management and Prevention. https://ginasthma.org/wp-content/uploads/2016/ 01/wms-GINA-2017-main-report-tracked-changes-for-archive.pdf (2018).

2. National Heart, Lung, and Blood Institute, National Asthma Education and Prevention Program. Expert Panel Report 3: Guidelines for the Diagnosis and Management of Asthma. Report No. 3, NIH Publication Number 08-5846 (NIH, Bethesda, 2007).

3. Barnes, P. J., Pedersen, S. \& Busse, W. W. Efficacy and safety of inhaled corticosteroids. New developments. Am. J. Respir. Crit. Care Med. 157, S1-53 (1998).

4. Suissa, S., Ernst, P., Benayoun, S., Baltzan, M. \& Cai, B. Low-dose inhaled corticosteroids and the prevention of death from asthma. N. Engl. J. Med. 343 332-336 (2000)

5. Williams, L. K. et al. Quantifying the proportion of severe asthma exacerbations attributable to inhaled corticosteroid nonadherence. J. Allergy Clin. Immunol. 128, 1185-1191 (2011). e1182.

6. Dekhuijzen, P. N. R. et al. Incidence of oral thrush in patients with COPD prescribed inhaled corticosteroids: effect of drug, dose, and device. Respir. Med. 120 , 54-63 (2016)

7. Dubus, J. C. et al. Local side-effects of inhaled corticosteroids in asthmatic children: influence of drug, dose, age, and device. Allergy 56, 944-948 (2001).

8. Lipworth, B. J. Systemic adverse effects of inhaled corticosteroid therapy: a systematic review and meta-analysis. Arch. Intern. Med. 159, 941-955 (1999).

9. Pinto, C. R. et al. Local adverse effects associated with the use of inhaled corticosteroids in patients with moderate or severe asthma. J. Bras. Pneumol. 39, 409-417 (2013).

10. Richter, K., Kanniess, F., Biberger, C., Nave, R. \& Magnussen, H. Comparison of the oropharyngeal deposition of inhaled ciclesonide and fluticasone propionate in patients with asthma. J. Clin. Pharmacol. 45, 146-152 (2005).

11. Buhl, R. Local oropharyngeal side effects of inhaled corticosteroids in patients with asthma. Allergy 61, 518-526 (2006).

12. Foster, J. M. et al. Higher patient perceived side effects related to higher daily doses of inhaled corticosteroids in the community: a cross-sectional analysis. Respir. Med. 100, 1318-1336 (2006).

13. Roland, N. J., Bhalla, R. K. \& Earis, J. The local side effects of inhaled corticosteroids: current understanding and review of the literature. Chest 126, 213-219 (2004).

14. Powell, H. \& Gibson, P. G. Inhaled corticosteroid doses in asthma: an evidencebased approach. Med J. Aust. 178, 223-225 (2003).

15. Price, D. et al. Real-life comparison of beclometasone dipropionate as an extrafine- or larger-particle formulation for asthma. Respir. Med. 107, 987-1000 (2013).

16. Amar, N. J., Moss, M. H., Kerwin, E. M., Li, J. \& Small, C. J. Safety and efficacy of beclomethasone dipropionate delivered by breath-actuated or metered-dose inhaler for persistent asthma. Allergy Asthma Proc. 37, 359-369 (2016).

17. Smith, M. J. \& Hodson, M. E. Twice daily beclomethasone dipropionate administered with a concentrated aerosol inhaler: efficacy and patient compliance. Thorax 41, 960-963 (1986).

18. Shaw, N. J. \& Edmunds, A. T. Inhaled beclomethasone and oral candidiasis. Arch. Dis. Child 61, 788-790 (1986).

19. Vandewalker, M., Hickey, L. \& Small, C. J. Efficacy and safety of beclomethasone dipropionate breath-actuated or metered-dose inhaler in pediatric patients with asthma. Allergy Asthma Proc. 38, 354-364 (2017).
20. Ellepola, A. N. \& Samaranayake, L. P. Inhalational and topical steroids, and oral candidosis: a mini review. Oral. Dis. 7, 211-216 (2001).

21. Knight, L. \& Fletcher, J. Growth of Candida albicans in saliva: stimulation by glucose associated with antibiotics, corticosteroids, and diabetes mellitus. J. Infect. Dis. 123, 371-377 (1971).

22. Fukushima, C. et al. Oral candidiasis associated with inhaled corticosteroid use comparison of fluticasone and beclomethasone. Ann. Allergy Asthma Immunol. 90, 646-651 (2003)

23. Rachelefsky, G. S., Liao, Y. \& Faruqi, R. Impact of inhaled corticosteroid-induced oropharyngeal adverse events: results from a meta-analysis. Ann. Allergy Asthma Immunol. 98, 225-238 (2007).

24. van Boven, J. F., de Jong-van den Berg, L. T. \& Vegter, S. Inhaled corticosteroids and the occurrence of oral candidiasis: a prescription sequence symmetry analysis. Drug Saf. 36, 231-236 (2013).

25. Toogood, J. H., Jennings, B., Greenway, R. W. \& Chuang, L. Candidiasis and dys phonia complicating beclomethasone treatment of asthma. J. Allergy Clin. Immunol. 65, 145-153 (1980).

26. National Institute for Health and Care Excellence. Asthma. https://www.nice.org uk/guidance/qs25/chapter/Quality-statements (2017).

27. Dolovich, D. Corr, McCormack, M., Ruffin, R., Obminski, G. \& Newhouse, M. Design and characteristics of a portable breath actuated, particle size selective medical aerosol inhaler. J. Aerosol Sci. 13, 1-7 (1982).

28. Dolovich, M. B. et al. Device selection and outcomes of aerosol therapy: evidencebased guidelines: American College of Chest Physicians/American College of Asthma, Allergy, and Immunology. Chest 127, 335-371 (2005).

29. Laube, B. L. et al. What the pulmonary specialist should know about the new inhalation therapies. Eur. Respir. J. 37, 1308-1331 (2011).

30. Salzman, G. A. \& Pyszczynski, D. R. Oropharyngeal candidiasis in patients treated with beclomethasone dipropionate delivered by metered-dose inhaler alone and with Aerochamber. J. Allergy Clin. Immunol. 81, 424-428 (1988).

31. Toogood, J. H., Baskerville, J., Jennings, B., Lefcoe, N. M. \& Johansson, S. A. Use of spacers to facilitate inhaled corticosteroid treatment of asthma. Am. Rev. Respir. Dis. 129, 723-729 (1984)

32. Emc+. Clenil Modulite 50, 100, 200, 250 micrograms inhaler. https://www medicines.org.uk/emc/medicine/21018 (2017).

33. Yau, W. et al. Examining licensed and unlicensed spacer use with nonextrafine beclometasone dipropionate treatment in a real-life patient population with asthma in the United Kingdom. NPJ Prim. Care Respir. Med. 27, 17008 (2017).

34. Mash, B., Bheekie, A. \& Jones, P. W. Inhaled vs oral steroids for adults with chronic asthma. Cochrane Database Syst. Rev. 1, CD002160 (2001).

35. Barry, P. W. \& O'Callaghan, C. A comparative analysis of the particle size output of beclomethasone diproprionate, salmeterol xinafoate and fluticasone propionate metered dose inhalers used with the Babyhaler, Volumatic and Aerochamber spacer devices. Br. J. Clin. Pharmacol. 47, 357-360 (1999)

36. t Jong, G. W., Eland, I. A., Sturkenboom, M. C., van den Anker, J. N. \& Strickerf, B. H. Unlicensed and off-label prescription of respiratory drugs to children. Eur. Respir. J. 23, 310-313 (2004)

37. Price, D. B. et al. Inhaler errors in the CRITIKAL study: type, frequency, and association with asthma outcomes. J. Allergy Clin. Immunol. Pract. 5, 1071-1081 (2017). e1079.

38. Reznik, M., Silver, E. J. \& Cao, Y. Evaluation of MDI-spacer utilization and technique in caregivers of urban minority children with persistent asthma. J. Asthma 51, 149-154 (2014).

39. Crespo-Lessmann, A., Plaza, V., Gonzalez-Barcala, F. J., Fernandez-Sanchez, T. \& Sastre, J. Concordance of opinions between patients and physicians and their relationship with symptomatic control and future risk in patients with moderatesevere asthma. BMJ Open Respir. Res. 4, e000189 (2017).

40. Price, D. et al. Complementing the randomized controlled trial evidence base Evolution not revolution. Ann. Am. Thorac. Soc. 11, S92-98 (2014).

41. Roche, N. et al. Integrating real-life studies in the global therapeutic research framework. Lancet Respir. Med. 1, e29-30 (2013).

42. Boulet, L. P. Perception of the role and potential side effects of inhaled corticosteroids among asthmatic patients. Chest 113, 587-592 (1998).

43. van Boven, J. F. et al. Enhancing respiratory medication adherence: the role of health care professionals and cost-effectiveness considerations. J. Allergy Clin. Immunol. Pract. 4, 835-846 (2016).

44. Britten, N., Stevenson, F., Gafaranga, J., Barry, C. \& Bradley, C. The expression of aversion to medicines in general practice consultations. Soc. Sci. Med. 59, 1495-1503 (2004).

45. Price, D. et al. Clinical and cost effectiveness of switching asthma patients from fluticasone-salmeterol to extra-fine particle beclometasone-formoterol: a retrospective matched observational study of real-world patients. Prim. Care Respir. 22, 439-448 (2013).

46. OPCRD. The Optimum Patient Care Research Database (OPCRD), https://opcrd.co uk/ (2016). 
47. Tate, A. R. et al. Exploiting the potential of large databases of electronic health records for research using rapid search algorithms and an intuitive query interface. J. Am. Med Inform. Assoc. 21, 292-298 (2014).

48. Cooper, V. et al. Patient-reported side effects, concerns and adherence to corticosteroid treatment for asthma, and comparison with physician estimates of side-effect prevalence: a UK-wide, cross-sectional study. NPJ Prim. Care Respir. Med. 25, 15026 (2015).

Open Access This article is licensed under a Creative Commons Attribution 4.0 International License, which permits use, sharing, adaptation, distribution and reproduction in any medium or format, as long as you give appropriate credit to the original author(s) and the source, provide a link to the Creative Commons license, and indicate if changes were made. The images or other third party material in this article are included in the article's Creative Commons license, unless indicated otherwise in a credit line to the material. If material is not included in the article's Creative Commons license and your intended use is not permitted by statutory regulation or exceeds the permitted use, you will need to obtain permission directly from the copyright holder. To view a copy of this license, visit http://creativecommons. org/licenses/by/4.0/.

(c) The Author(s) 2019 